\title{
Manifestações do conhecimento estatístico de professores em formação continuada
}

\author{
Manifestations of teachers' statistical knowledge in continuing education
}

\author{
Gabriel José Cavassin Fabri ${ }^{1}$ \\ Maria Lucia Panossian ${ }^{2}$ \\ Valderez Aparecida Aluiz Amin ${ }^{3}$
}

Natalia Mota Oliveira ${ }^{4}$

\section{Resumo}

Este artigo apresenta a análise sobre o conhecimento estatístico manifestado por professores nas ações do projeto de extensão Oficina Pedagógica de Matemática (OPM), organizado a partir dos pressupostos da Atividade Orientadora de Ensino que, por sua vez, pauta-se nos fundamentos da Teoria Histórico-Cultural e Teoria da Atividade. Para tal, foram analisados episódios nos quais há manifestações dos professores diante de uma situação desencadeadora de aprendizagem de conceitos estatísticos. Como resultado, foi possível reconhecer que a situação, que foi elaborada considerando relações essenciais do conhecimento estatístico a partir de seu movimento histórico e lógico, desencadeou nos professores participantes necessidades de estabelecimento de nexos entre os conceitos da Estatística. As necessidades evidenciadas pela situação e no processo de organização da formação de forma geral desencadearam ações de pesquisa e de síntese por parte dos professores, o que revela a importância de projetos como a OPM para a formação de professores do ensino básico.

Palavras-chave: Conhecimento Estatístico; Atividade Orientadora de Ensino; Experimento Formativo; Oficina Pedagógica de Matemática.

\begin{abstract}
This article presents the analysis of the statistical knowledge manifested by teachers in the actions of the extension project Pedagogical Workshop of Mathematics (OPM), organized based on the assumptions of the Teaching Orienteering Activity, which, in turn, is based on the foundations of Historical-Cultural Theory and Activity Theory. To this end, episodes were analyzed in which there are manifestations by teachers in the face
\end{abstract}

Submetido em: 30/10/2020 - Aceito em: 01/02/2021 - Publicado em: 29/05/2021

${ }^{1}$ Mestrando do Programa de Pós-Graduação em Formação Científica, Educacional e Tecnológica (PPGFCET) da Universidade Tecnológica Federal do Paraná, Brasil. E-mail: fabrig@alunos.utfpr.edu.br. ORCID: https://orcid.org/0000-0002-6207-3526

2 Doutora em Educação pela Universidade de São Paulo. Professora do Programa de Pós-Graduação em Formação Científica, Educacional e Tecnológica (PPGFCET) da Universidade Tecnológica Federal do Paraná, Brasil. E-mail: mlpanossian@utfpr.edu.br. ORCID: https://orcid.org/0000-0001-6821-4273

3 Mestranda do Programa de Pós-Graduação em Educação em Ciências e em Matemática (PPGECM) da Universidade Federal do Paraná, Brasil. E-mail: valderez.aluiz@gmail.com. ORCID: https://orcid.org/00000003-1585-4159

4 Licencianda em Matemática da Universidade Tecnológica Federal do Paraná, Brasil. E-mail: nataliaoliveira@alunos.utfpr.edu.br. ORCID: https://orcid.org/0000-0001-5847-4485 
DOI: $10.20396 /$ zet.v29i00.8661815

of a situation that triggers the learning of statistical concepts. As a result, it was possible to recognize that the situation, which was elaborated considering essential relations of statistical knowledge from its historical and logical movement, triggered in the participating teachers the need to establish links between the concepts of Statistics. The needs evidenced by the situation and in the process of organizing training in general triggered research and synthesis actions by teachers, which reveals the importance of projects such as OPM for the training of basic education teachers.

Keywords: Statistical Knowledge Teaching Orienteering Activity; Teaching Experiment; Pedagogical Workshop of Mathematics.

\section{Introdução}

Ao tratar a prática pedagógica como fonte de fenômenos a serem observados e analisados em pesquisas na área de ensino, tem-se o conhecimento do professor como objeto de estudo. Nesse sentido, o objetivo deste trabalho é analisar o conhecimento estatístico dos professores do $1^{\circ}$ ao $5^{\circ}$ ano dos anos iniciais do ensino fundamental manifestados a partir de uma situação desencadeadora de aprendizagem apresentada na Oficina Pedagógica de Matemática $^{5}(\mathrm{OPM})$.

Ao observar as diferentes perspectivas em relação à apropriação do conhecimento estatístico, nota-se maneiras distintas de abordar o problema - uma dessas seria a utilização de questionários para reconhecer a relação dos professores com esse conteúdo, aplicando métodos estatísticos de análise, como a proposta de Oliveira Júnior (2018), para avaliação das atitudes dos professores. De outra forma, Silva, Alves, Pietropaolo \& Amorim (2020) centram-se na discussão da Estatística na Educação Básica a partir das habilidades profissionais dos professores de Matemática e pedagogos que ministram aulas sobre conceitos estatísticos, baseados em Shulman (1987). Já Conti, Carvalho \& Carvalho (2016) adotam o Letramento Estatístico (Gal, 2004) como fundamento teórico para o estudo do conhecimento do professor.

Outros autores apresentam diferentes modos de estudo e pesquisa sobre o conhecimento dos professores. Entretanto, aqui é adotada a compreensão sobre o processo de formação de professores e apropriação de conhecimentos na Oficina Pedagógica de Matemática sustentada pelos pressupostos da Atividade Orientadora de Ensino (Moura et al., 2016), pautada na Teoria da Atividade (Leontiev, 1978).

A Oficina Pedagógica de Matemática pode ser compreendida como um processo de materialização da práxis docente. Este projeto extensionista da Universidade Tecnológica Federal do Paraná, campus Curitiba, visa a estabelecer o trabalho coletivo entre os professores em exercício nas escolas públicas da Educação Básica e os estudantes da licenciatura em Matemática e pós-graduandos da área de ensino. Essa iniciativa tem suas raízes em projeto homônimo realizado na Universidade de São Paulo, desde a década de 80, e expandido para outras instituições por integrantes do Grupo de Estudos sobre Atividade Pedagógica (GEPAPe). Conforme Moura (1988), a OPM era reconhecida como um ambiente de criação de materiais e discussão crítica da organização do ensino de matemática, buscando

\footnotetext{
${ }^{5}$ Site do projeto: https://sites.google.com/view/opm-2019
} 
DOI: $10.20396 /$ zet.v29i00.8661815

engendrar novas formas de trabalho docente. Atualmente, o objetivo é propiciar um espaço de aprendizagem docente onde teoria e prática constituem uma unidade sustentada pela Atividade Orientadora de Ensino como base teórico-metodológica.

Considerando este espaço formativo e o objetivo de analisar as manifestações dos conhecimentos estatísticos destes professores, este texto se divide em algumas seções. Primeiramente, é importante discutir a fundamentação teórica do projeto, a Atividade Orientadora de Ensino, que orientou tanto o processo de formação continuada quanto as análises deste trabalho. Depois, voltam-se os olhares para o movimento lógico da Estatística considerada em todo o processo. A partir dela é que se organizaram as ações da Oficina Pedagógica de Matemática, que são analisadas enquanto um experimento formativo na terceira seção. Por fim, a quarta, a quinta e a sexta seções se dedicam aos episódios destacados para a análise dos dados.

\section{Atividade Orientadora de Ensino}

No que tange ao campo da Educação Estatística, há um modo particular de estudo dos fenômenos relacionados- ao conhecimento dos sujeitos, considerando as competências de Literacia, Pensamento e Raciocínio Estatístico (Campo, Wodewotzki \& Jacobini, 2013). No entanto, não foi a partir dessas competências que ocorreu a organização da Oficina Pedagógica de Matemática. A orientação teórico-metodológica que sustenta esse projeto de extensão tem como seus pressupostos a Atividade Orientadora Ensino, que apresenta um modo próprio de estudo sobre a apropriação do conhecimento, e a formação dos professores de forma geral e de forma particular, no tocante aos conhecimentos estatísticos. Ao considerar professor e estudante como sujeitos em atividade, a Atividade Orientadora de Ensino (AOE) (Moura et al., 2016) permite compreender o processo de formação destes a partir da intencionalidade de suas ações. Ao receber contribuições dos integrantes do Grupo de Estudos e Pesquisas na Atividade Pedagógica (GEPAPe/FEUSP), a Atividade Orientadora de Ensino firma-se como base teórico-metodológica para compreensão do processo de ensino-aprendizagem a partir dos pressupostos da Teoria Histórico-Cultural (Vygotsky, 1998) e da Teoria da Atividade (Leontiev, 1978).

Entende-se por 'atividade' a unidade de análise do processo psíquico revelada quando os motivos do sujeito coincidem com o objeto para o qual ele se dirige. Nesse processo psíquico, sujeitos em atividade realizam ações e operações com a motivação de atingir um objetivo que supra uma necessidade individual ou coletiva. Assim, esses elementos, por constituírem a atividade dos sujeitos, tornam-se estruturantes da Atividade Orientadora de Ensino enquanto relação entre a atividade do professor e dos estudantes.

A atividade de ensino é neste sentido o processo psíquico do professor que se vê diante da necessidade de organização do ensino. Ela "é criação humana para desenvolver o modo humano de apropriação de conhecimentos necessários para inserir novos sujeitos em atividades coletivas que tenham por objetivo a satisfação de necessidades [...] desenvolvidas historicamente" (Moura, Araújo \& Serrão, 2019, p. 416). Partindo do pressuposto que o 
processo de organização do ensino é intencional, compreende-se que a atividade de ensino exige do professor constante estudo, análise, síntese e reflexão sobre a teoria e prática. A atividade de ensino "forma [o professor] na medida em que este planeja a ação inicial e deve permanecer num processo de avaliação contínuo das ações desenvolvidas em aula, para que seja atingido o objetivo proposto" (Moura, 1996, p. 42).

Neste movimento de organizar o ensino buscando potencializar o desenvolvimento dos estudantes, entende-se que as ações do professor têm por intenção desencadear a atividade de aprendizagem. Para que esta ocorra, espera-se que o motivo do estudante estar na escola seja a apropriação de conhecimentos (Moura et al., 2010). Assim, "os conhecimentos teóricos são ao mesmo tempo objeto e necessidade na atividade de aprendizagem" (Moura et al., 2010, p. 215). Esse tipo conhecimento é apropriado por formas teóricas de pensamento.

Davydov (1988) considera como formas de pensamento humano o empírico e o teórico, ambos sustentados por abstrações, generalizações e deduções. O pensamento empírico é baseado na realidade objetiva-sensorial do sujeito, enquanto o pensamento teórico opera sobre conceitos. "O conceito intervém aqui como forma da atividade mental mediante a qual se reproduz o objeto idealizado e seu sistema de relações" (Davydov, 1988, p. 300, tradução nossa). Segundo Kopnin, “o pensamento teórico reflete o objeto no aspecto das relações internas e leis do movimento deste, cognoscíveis por meio da elaboração racional dos dados do conhecimento empírico" (1978, p. 152). Logo, o pensamento teórico deriva das relações entre os conceitos idealizados pelo sujeito e os dados da realidade objetiva, compreendidos como nexos conceituais internos e externos.

O reconhecimento dos nexos conceituais internos ocorre por meio do estudo do movimento histórico-lógico, compreendido como o processo de reconhecer as necessidades que desencadearam determinada forma de conhecimento no movimento histórico da experiência humana, bem como os nexos entre os conceitos que constituem esse conhecimento. Essas relações entre os conceitos formam o aspecto lógico que "reflete não só a história do próprio objeto como também a história do seu conhecimento" (Kopnin, 1978, p. 186).

No processo de organização do ensino, o professor propõe situações que desencadeiam nos estudantes a necessidade do conhecimento teórico, compreendidas pela AOE como "situações desencadeadoras de aprendizagem" (Moura et al., 2016). Para elaborar uma situação desencadeadora, é necessário o reconhecimento consciente do professor sobre o conhecimento teórico a ser conduzido. Ou seja, é preciso reconhecer os nexos conceituais internos e externos da área do conhecimento que pretende ensinar — no caso desta pesquisa, os nexos conceituais da Estatística.

\section{Considerações sobre o movimento lógico e histórico do conhecimento estatístico e seus nexos conceituais}

O estudo do movimento lógico e histórico do conhecimento e o desvelamento de 
DOI: $10.20396 /$ zet.v29i00.8661815

nexos conceituais fazem parte da organização do ensino pautada na Atividade Orientadora de Ensino. É característico desse estudo o reconhecimento das necessidades que resultaram de alguma forma na objetivação dos conceitos, que particularmente para este estudo são os estatísticos. Para tal, foi necessária a pesquisa em fontes históricas que tratam sobre o desenvolvimento da ciência estatística.

Moura et al. (2019), ao trazerem considerações sobre o movimento lógico e histórico da Estatística, apresentam a possibilidade de os registros rupestres do Período Paleolítico serem formas de representações pictográficas, com a finalidade de compartilhar informações com o seu coletivo. Essa consideração revela dois aspectos essenciais para o desenvolvimento da Estatística: transformação de dados brutos (natureza) em dados pensados, que seriam aqueles que já passaram por algum tipo de análise ou tratamento; e a produção de meios de representação de informações.

Poubel e Sad (2014) registram que a ciência estatística "era, a princípio, praticada de modo empírico por meio de contagens quantitativas, mas lentamente, envolveu profissionais, até vir a tornar-se o método para a análise e estudo dos fenômenos sociais, sistematizados numericamente." (p. 21). Ao observar a origem da palavra da estatística, Memória (2004) atribui o surgimento à palavra latina status, estado, pois por muito tempo era a única fonte de coleta, estudo e apresentação de dados quantitativos. No entanto, Memória (2004) aponta que,

$\mathrm{Na}$ verdade, sua feição essencial é a de ser um conjunto de métodos (métodos estatísticos), especialmente apropriado, no dizer de George Udny Yule (1871 - 1951), ao tratamento de dados numéricos afetados por uma multiplicidade de causas (Memória, 2004, p. 10).

Lopes e Meirelles (2005) entendem a Estatística como "a arte e a ciência de coletar, analisar e fazer inferências a partir de dados" (p. 3). Na perspectiva de Wild, Utts e Horton (2018), a Estatística é uma forma de "pensar como pensar os dados" (p. 7), projetando uma percepção do mundo real, e afirmam como uma necessidade humana fundamental o ser capaz de aprender como a realidade opera com a utilização de dados, considerando seus níveis de incerteza.

Mesmo que as considerações sobre o que é Estatística possam ser modificadas entre os autores, a importância dos dados é questão nuclear entre elas. Em outras palavras, um ensino de Estatística que busque a formação teórica dos conceitos (Davydov, 1988) tem como um dos objetivos evidenciar a necessidade dos dados, que apenas possuem sentido quando coletados e possivelmente analisados.

O escopo atual e o conteúdo intelectual da estatística são resultados de processos evolutivos que envolveram tanto o lento progresso quanto os saltos de desenvolvimentos devido aos insights de grandes intelectuais e visionários, todos afetados pela realidade de sua época e dos desafios reconhecidos no mundo em que eles viveram. Mas não alcançou um estado final fixo. Essa continua a evoluir e crescer em resposta aos novos desafios e oportunidades da realidade mutável em que vivemos agora (Wild, Utts \& Horton, 2018, p. 10, tradução nossa). 
Alguns autores, como Bernstein (2018) e Tabak (2004), indicam Johan Graunt (16201674) como um dos precursores da Estatística moderna e responsável por contabilizar as mortes e nascimentos, considerando as variáveis de sexo, idade, estado civil e religião. Tabak (2004) aponta que Graunt foi o primeiro a desenvolver análises relacionando as causas das mortes com os sujeitos. Bernstein (2018) indica que o teórico não evidenciava o que o inspirou para produzir as "Tábuas de Mortalidade", apenas que tinha um prazer em fazer algo inovador, que poderia melhorar a qualidade do tratamento de problemas da sociedade. O que se destaca do trabalho de Graunt é a utilização de amostra para estimar informações para a população mesmo não tendo consciência disso, pois utilizou o conjunto de dados que as igrejas possuíam - ainda que reconhecesse que os dados não eram fidedignos. Esse tratamento objetivava deduzir informações para a população, o princípio da inferência Estatística.

O trabalho pioneiro de Graunt revelou conceitos teóricos básicos necessários à tomada de decisões sob condições de incerteza. Amostragens, médias e noções do que é normal e compõem a estrutura que iria mais à frente, abrigar a ciências da análise estatística, colocando a informação a serviço da tomada de decisões e influenciando nossos graus de crença sobre eventos futuros (Bernstein, 2018, p. 86).

$\mathrm{Na}$ época, suas aproximações foram consideradas boas, mas alguns de seus resultados foram questionados. O episódio histórico de Graunt elevou a consideração pelos dados, tratando-os de uma forma revolucionária à sua época. Percebe-se que o conhecimento desenvolvido surgiu da necessidade de estabelecer um resumo da realidade vivenciada apresentando resultados que modificaram a percepção dos sujeitos quanto a seu povo.

Devido à necessidade social, Graunt atribuiu sentido a suas ações, permitindo-o ressignificar a análise estatística. Esse processo evidencia como o meio interfere no desenvolvimento pessoal, e consequentemente, no processo de elaboração de conceitos da ciência estatística. No entanto, mesmo que o problema de Graunt fosse de origem prática, no caso formular tabelas de mortalidade, os resultados dos seus estudos não foram contidos para uma solução particular. Para tal, foi necessário sistematizar medidas resumo e formas de representação que possibilitassem descrever melhor as informações que obtinha.

Este é um dos processos que constituem o movimento histórico e lógico da ciência estatística e que auxilia a compreender que o desenvolvimento do conhecimento científico pode ser reconhecido em necessidades humanas. Tal estudo requer aprofundamento, mas Moura et al, (2019), a partir do estudo desse movimento, apresentam quatro relações essenciais do conhecimento estatístico a serem consideradas no processo de ensino: o movimento de variabilidade de um fenômeno em determinado tempo e espaço; a percepção e observação da frequência de um fenômeno; a demonstração de regularidades; a realização de previsões e possibilidades da ocorrência de um fenômeno. Ainda, os autores indicam que:

Deste modo, o objeto da Estatística se revela como um método de estudo sobre a ocorrência de determinado fenômeno e seu objetivo é, percebendo suas regularidades ou não, estabelecer previsões e hipóteses estatísticas. Portanto, as atividades de ensino devem contemplar este objetivo. (Moura et al., 2019, p. 6). 
DOI: 10.20396/zet.v29i00.8661815

Essas relações essenciais e o processo histórico enunciado foram considerados para a organização de uma situação desencadeadora de aprendizagem, que buscou estabelecer necessidades próximas àquelas que tensionaram a humanidade a produzir novos modos de estudo dos dados. Assim, foi elaborada a situação apresentada aos professores em formação durante a Oficina Pedagógica de Matemática, com a intenção de que se apropriassem de algumas relações do conhecimento estatístico envolvendo a necessidade humana de observação de regularidades de um fenômeno e realização de previsões, recorrendo também a noções de taxas e diferentes formas de representação como gráficos e tabelas. Tais relações foram objetivadas no experimento formativo.

Vale ressaltar que esse estudo histórico não possui a característica de gerador de contexto, nem pretende recapitular todo o processo histórico. Ao se trazer o lógico-histórico, busca-se apreender os movimentos aos quais a humanidade foi exposta e incorporá-los em uma situação desencadeadora de aprendizagem. Essa é considerada a ação central no processo da Atividade Orientadora de Ensino, enquanto base teórico-metodológica para organização do ensino que pretende provocar a tensão criativa dos estudantes, considerando o movimento de produção de conhecimentos próximos àqueles que a humanidade vivenciou.

\section{Experimento Formativo: as ações na Oficina Pedagógica de Matemática}

Definiu-se como objetivo da pesquisa apresentada neste artigo analisar o conhecimento estatístico manifestado por professores da Educação Básica durante o processo de resolução de uma situação desencadeadora de aprendizagem na Oficina Pedagógica de Matemática. A OPM é um projeto de extensão em desenvolvimento na Universidade Tecnológica Federal do Paraná desde 2015, e tem por objetivo promover entre professores da universidade, professores da rede básica de ensino e estudantes da graduação (Licenciatura em Matemática e Pedagogia) e pós-graduação a articulação teoria/prática (práxis) que fundamenta suas ações dentro da atividade de ensino de matemática.

Os estudos e trabalhos desenvolvidos entre os participantes da OPM, considerada como espaço de aprendizagem da docência, (Moraes, Arrais, Gomes, Graciliano \& Vignoto, 2012; Moraes, Lazaretti \& Arrais, 2019), estão sustentados sobre os fundamentos da Teoria Histórico Cultural, Teoria da Atividade e da Atividade Orientadora de Ensino (Moura, 2010), enquanto base teórica e metodológica. Neste sentido, reconhece-se que todos os participantes da OPM possuem uma necessidade (organização do ensino) e constituem um coletivo direcionado a um objeto (apropriação dos conhecimentos científicos pela via do pensamento teórico). Durante o ano de 2020, os estudos na OPM foram direcionados de forma particular ao processo de organização do ensino de Estatística. Além disso, para que a pesquisa fosse realizada junto a esse projeto de extensão, foi submetida e aprovada junto ao comitê de ética da instituição. As ações da OPM acontecem de forma contínua, com reuniões regulares entre a equipe executora do projeto e os participantes. No primeiro semestre de 2020, a equipe contava com 15 membros da equipe executora, sendo 4 professoras de ensino superior, 5 pósgraduandos de mestrado profissional, 2 pós-graduandos de mestrado acadêmico e 4 
estudantes de graduação em Licenciatura em Matemática. Além destes, participaram da OPM 13 professores da rede municipal de ensino de Piraquara que lecionam nos anos iniciais do ensino fundamental.

Desta forma e pela interação entre professores de diferentes níveis de ensino e de formação, reconhece-se na OPM um espaço propício para a realização de pesquisas sobre formação docente. Entende-se que tais pesquisas têm caráter semelhante a um experimento formativo, haja vista que tem caráter qualitativo com participação ativa dos pesquisadores que se baseiam nas observações coletadas para planejamentos futuros e possuem orientação para a formação de professores (Cedro, 2008). Isso se deve às características da própria OPM, em que, assim como em um experimento formativo, no desenvolvimento das ações do projeto os professores "se apropriam de forma substancial de uma gama de conhecimentos vinculados à atividade educativa" (Cedro, 2008, p. 198).

Este movimento formativo da OPM se revela nas diferentes ações de todos os sujeitos participantes. São características desse movimento a fluência — tudo se modifica a todo momento - e a interdependência — tudo está relacionado com tudo (Caraça, 1978). A fluência e interdependência do fenômeno de formação continuada dos docentes se revelam em inúmeras relações dos participantes, das quais destacam-se: a relação entre os participantes; as com o objeto do conhecimento (Estatística); com a base teóricametodológica que organiza as ações do projeto (AOE); com o formato em que está ocorrendo o projeto, via plataformas virtuais, devido ao momento pandêmico vivenciado; as relações dos participantes com o ambiente escolar, etc. Estas relações influenciam o processo formativo que ocorre na Oficina Pedagógica de Matemática.

$\mathrm{Na}$ impossibilidade de abranger e explicitar esse movimento formativo, faz-se o recorte isolado (Caraça, 1978) que possibilita uma melhor análise do fenômeno, que nesta pesquisa se refere ao conhecimento estatístico manifestado pelos professores dos anos iniciais no movimento da OPM. Assim, o isolado escolhido para ser analisado foi a manifestação deste fenômeno no movimento dos professores em resposta ao problema apresentado pela situação desencadeadora de aprendizagem 'O Diário da Peste Bubônica' (Silva et al., 2020). Tal situação foi elaborada por participantes da equipe executora da OPM para ser apresentada aos demais participantes do projeto que são professores dos anos iniciais da Educação Básica.

O recorte em isolados pressupõe um erro inicial no sentido de que ele é separado do sistema de relações em que se encontra. Então, ao analisar o conhecimento estatístico dos professores resolvendo uma situação no movimento da OPM, separa-se, por exemplo, do movimento de formação anterior vivenciado por este mesmo professor, ou de outras apropriações sobre o conhecimento estatístico que este professor possa ter vivenciado e que influenciam suas ações na OPM.

A situação 'O Diário da Peste Bubônica' apresenta a personagem Augusta que, no contexto pandêmico da França nos anos de 1720 e 1721, narra em seu diário as dificuldades enfrentadas e informações sobre números de mortos e sobreviventes da peste. Trata-se de uma história virtual elaborada com personagens fictícios, mas que vivenciam um problema de 
DOI: $10.20396 /$ zet.v29i00.8661815

isolamento social da época e que pode ser concebido também na época atual da Pandemia de covid-19. As informações quantitativas vão sendo apresentadas gradualmente à medida que se apresentam trechos do diário, como exposto nas Figuras 1, 2 e 3.

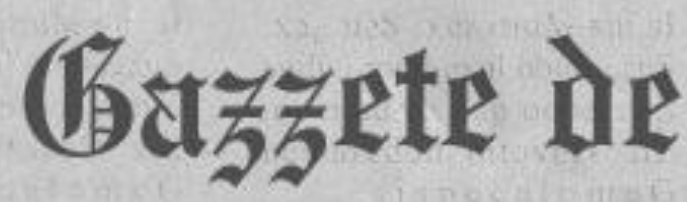 \\ 20 de dexcmbro de 1720 \\ Interdiction de circulation}

Rei Luis XV indicou o Segundo as autoridades fechamento das cidades locais, a cidade de Arles para diminuiçầo do declarou mil mortes. Já na contágio da Peste Negra. cidade de Provença foram Também indicou que as declaradas trezentas pessoas evitassem a mortes.

circulação pela cidade.

Fonte: Silva et al., 2020, p. 6.

\section{(bigazbete ide}

30) de janciiro de 1721

\section{Cinq mois de terreur!}

A populaçâo de Arles cai isolamento domiciliar para de 23 mil para $20 \mathrm{mil}$ tratar os infectados. Total habitantes em apenas 5 de infectados já chega a 3 meses de peste! A nova mil em Arles.

estratégia do governo é o

Figura 2 - Segundo trecho do diário de Augusta

Fonte: Silva et al., 2020, p. 6. 


\section{(bastzate de}

15 de junho de 1721

\section{6 mille morts!}

Arles já chegou ao oitavo registrados foram 6 mil
mês de isolamento. Até o mortes em Arles contando
momento, foram com 8 mil infectados.

Figura 3 - Terceiro trecho do diário de Augusta

Fonte: Silva et al., 2020, p. 7.

Para a resolução da situação, espera-se que os participantes organizem os dados apresentados no diário em tabelas ou outra forma. As informações contidas no diário permitem que se chegue somente no registro da Tabela 1, sendo os dados ocultos tratados como não registrados (NR).

Tabela 1 - Dados quantitativos presentes na situação

\begin{tabular}{|l|l|l|l|l|l|l|}
\cline { 2 - 7 } \multicolumn{1}{c|}{} & Datas & $20 / 12 / 1720$ & $30 / 01 / 121$ & $01 / 02 / 1721$ & $15 / 06 / 1721$ & $20 / 08 / 1721$ \\
\hline $\begin{array}{c}\text { Total de } \\
\text { mortes } \\
\text { registradas } \\
\text { nas cidades }\end{array}$ & Arles & 1000 & 3000 & NR & 6000 & NR \\
\cline { 2 - 7 } & Provença & 300 & NR & 2000 & NR & 6000 \\
\hline
\end{tabular}

Fonte: Adaptado de Silva et al., 2020

Ao fim da situação, os personagens têm um problema a resolver em relação à manutenção ou não do isolamento em que se encontram, em que eles se perguntam: "O que fazer com tantos números que o governo nos manda pelos jornais?’.

Esperava-se que, a partir da leitura da situação e do problema desencadeador proposto, os professores discutissem a organização dos dados, a análise estatística a partir das variáveis (quantidade de mortos, quantidade de doentes e quantidade de recuperados), a percepção de regularidades, bem como que tivessem condições de propor uma solução coletiva. Neste movimento, a expectativa era de potencializar formas de pensamento teórico e reconhecimento dos nexos conceituais da Estatística apresentados por Moura et al. (2019).

Os participantes da OPM discutiram esta situação durante dois encontros de duas horas de duração. A situação foi encaminhada antecipadamente para resolverem e apresentarem uma solução individual no primeiro encontro, que a partir de agora será identificado como E1. Durante a ocasião, as soluções apresentadas pelos professores foram 
discutidas em busca de uma solução coletiva. Neste momento também foram discutidos os conceitos de taxas, variáveis e formas de organização de dados, além da apresentação de uma tabela com os dados acumulados nas duas cidades após o surto da doença e o número de habitantes de cada localidade. Para o segundo encontro, a partir de agora identificado como E2, os professores deveriam rever a solução individual a partir dos novos dados apresentados e estabelecer articulação com os elementos da Atividade Orientadora de Ensino, a partir de leitura previamente realizada, reconhecendo necessidades e ações desencadeadas pela situação, bem como os conceitos estatísticos discutidos. Para analisar os dados das soluções, foram utilizadas as siglas E1 ou E2 para os encontros e, para os professores, PA, PB, PC, PD, PE, PF, PG e PH, além da indicação do tipo de registro (vídeo ou registro escrito).

Devido ao objetivo deste artigo estar relacionado às manifestações do conhecimento estatístico dos professores, optou-se por apresentar essas manifestações por meio de cenas que constituem os episódios, que conforme Moura (2004), "revelam a natureza e qualidade das ações em um isolado" (p. 273). Tais episódios e cenas foram extraídos das discussões registradas no formato escrito e na apresentação oral das soluções dos professores.

O primeiro episódio está relacionado às necessidades que foram desencadeadas pela situação. O segundo episódio destaca as ações dos sujeitos durante a discussão e o processo de resolução da situação. No último episódio, são destacadas as manifestações dos participantes sobre o conhecimento estatístico e suas relações.

\section{Episódio 1: As necessidades despertadas pela situação}

O ensino organizado a partir dos elementos da Atividade Orientadora de Ensino possui como ação central a proposição de uma situação desencadeadora de aprendizagem, cujo objetivo é gerar necessidades aos sujeitos (Moura, Araújo \& Serrão, 2019). Contudo, estas necessidades geradas nos participantes nem sempre estiveram relacionadas à compreensão dos conceitos estatísticos durante a resolução do problema. Foi possível perceber que os professores manifestaram também necessidade de conhecer a realidade e o processo de coleta de dados do contexto histórico apresentado na situação.

Assim, a primeira cena deste episódio que se desvela é a tentativa dos professores de compreender como o contexto histórico e as ferramentas da época influenciam na confiabilidade, atualização e divulgação dos dados. Essa necessidade foi demonstrada nas falas de dois professores que ficaram curiosos sobre como era o recolhimento de dados da época e se não haviam adulterações nas informações dos jornais. Na fala de uma das professoras,

Senti a necessidade de ter outros dados, principalmente em relação aos métodos de pesquisa utilizados na época. Como eu poderia pensar em alguma estratégia para resolver o problema se 'a gente' não sabia quais eram os métodos de pesquisa e levantamento de dados para resolver esse problema? (E1, PD, vídeo).

Um outro professor (PC) indica a possibilidade de fazer uma pesquisa local e verificar se os dados estão de acordo com os informados pelo governo. Contudo, é importante ressaltar 
que não necessariamente a quantidade de casos e de mortes estão distribuídas homogeneamente pela região. $\mathrm{O}$ professor ainda indica que se a pesquisa local obtiver dados semelhantes aos divulgados pelo governo, então poderia considerar as informações do governo como verdadeiras.

Mas o que significa um levantamento de dados ser verdadeiro para a Estatística? Podemos considerar que isso ocorre quando analisamos uma amostra significativa. Isso decorre da consideração do momento histórico vivido pela personagem. Assim como ocorreu na Inglaterra, Graunt obteve dados que representavam informações de uma parcela da população, e dessas, estendeu conclusões sobre toda população (Bernstein, 2018). Mesmo que os estudos epidemiológicos sejam censitários, contabilizando o número absoluto de habitantes e dos casos de uma doença e suas consequências, essa é uma possibilidade distante para a época narrada na situação. Então, se a região da cidade em que Augusta mora não for significativa para a situação de toda a cidade, é possível que os dados recolhidos fossem muito divergentes dos apresentados nos jornais. Então a pesquisa dela seria falsa? Não, ela só não poderia, necessariamente, ser usada para analisar a situação da cidade toda. Augusta precisaria escolher com cuidado a amostra da população.

Assim, podemos perceber por essa cena que alguns professores sentiram necessidades relacionadas ao contexto histórico e desconfiaram do método estatístico utilizado no recolhimento de dados, mas a alternativa proposta não tinha, ainda, os cuidados necessários para uma análise estatística.

Outras três professoras (PA, PD e PE) sentiram falta de dados numéricos, e essas contribuições constituem a segunda cena. A omissão da população das cidades no registro do diário era intencional, justamente para desencadear nos professores a necessidade desses dados e mostrá-los que é necessário cuidado ao escolher quais variáveis podem ser usadas como critérios de comparação. Sem a informação da população das regiões não era possível estipular as taxas de mortalidade (quantidade de mortes por total de habitantes) e de incidência (quantidade de casos por total de habitantes). A análise das taxas de letalidade (quantidade de mortes por quantidade de casos) apenas mostrava o quão grave era a doença, e que tal taxa poderia ser alta mesmo que pouquíssimas pessoas fossem atingidas. Alguns professores destacaram que a cada 4 infectados, 3 morreriam, contudo, por não sentirem falta do número de habitantes, demonstraram não estabelecer comparações entre as cidades, sem a análise de que o impacto de 6 mil mortes em uma cidade com uma pequena quantidade de habitantes é muito diferente do que seria em uma grande capital, com maior número de habitantes.

Além disso, uma das professoras (PF) destacou que sentiu falta de uma planilha com número de infectados, mortos e recuperados. É válido destacar que a elaboração de uma planilha que pudesse ajudar na decisão de Augusta só seria possível com auxílio dos conceitos estatísticos, principalmente do reconhecimento das variáveis e taxas, já que apenas os dados numéricos não eram suficientes e a organização e representação bidimensional dos dados (seja em planilhas ou gráficos) requer uma análise prévia do que cada informação 
representa e como se relacionam, podendo assim selecionar as variáveis e calcular as taxas que seriam relevantes para a resolução do problema. Ao fim deste episódio, é possível destacar que as necessidades manifestadas pelos sujeitos já nos permitem reconhecer o seu processo em direção à apropriação dos conceitos estatísticos. Neste caso, constataram-se as seguintes situações: alguns professores não haviam se apropriado dos conceitos de taxa e de variável, o que foi observado por não sentirem necessidade de identificar o número de habitantes de cada cidade, e outros não se mobilizaram em função de responder ao questionamento, atentando-se a questões sociais. Houve professores que desencadearam ações de pesquisa e de estudo, as quais serão analisadas no próximo episódio.

\section{Episódio 2: Ações dos professores desencadeadas pela situação}

No segundo episódio, evidenciam-se algumas ações dos professores participantes durante a análise da situação desencadeadora de aprendizagem (SDA) em busca da sua resolução.

A primeira cena deste episódio revela a intenção dos participantes de analisar a situação somente com os dados que estavam descritos no diário de Augusta. Percebendo que os dados apresentados não eram suficientes, alguns participantes procuraram obter mais informações para analisar a situação de acordo com o contexto histórico daquela época. Essa ação foi demonstrada na fala de uma professora (PA), que chegou à conclusão de que só os dados da situação não eram suficientes para que ela tomasse uma posição referente a isolar-se ou não.

Eu fui para o lado das informações que eu tinha e o que eu precisei pesquisar sobre a doença. Quando eu abri o diário e comecei a ler, eu gosto muito de falar de estatística e fazer gráficos e comparar muito as informações 'pra' não ter nenhum equívoco e eu vi muitas informações contraditórias (E1, PA, vídeo).

Além disso, após o primeiro encontro, os organizadores apresentaram uma tabela com dados completos das duas cidades após o surto e convidaram os professores a reelaborarem suas respostas. Neste movimento, duas professoras reafirmaram suas decisões sobre o isolamento a partir do conceito de taxa apresentado, demonstrando que o compreenderam e dele se utilizavam para interpretar os dados e tomar decisões, movimentos próprios do conhecimento estatístico. Apesar de muitos professores não buscarem reformular suas respostas, a professora PA foi além, procurando entender mais sobre o conceito de variável, que foi apresentado de forma geral. Ela reafirmou a definição de variáveis como a característica a ser observada e apresentou explicações e exemplos de cada tipo de variável qualitativa e quantitativa.

Quando os professores participantes foram questionados sobre as necessidades que a situação gerou em cada um e quais os dados que ainda faltavam para chegarem a uma conclusão, a mesma professora afirmou ter feito uma lista de dados que estavam faltando, tanto os socioeconômicos da época quanto os numéricos. Neste momento, é nítida a ação desenvolvida pela professora - além da análise da situação, a busca por mais elementos que a respaldassem diante da situação. 
A segunda cena revela uma ação de articulação da situação apresentada com a estrutura da Atividade Orientadora de Ensino. Foi disponibilizado um texto para leitura prévia aos participantes com o intuito de se familiarizarem com a AOE e foi solicitado que, com base no texto, montassem um esquema articulando a situação apresentada com os elementos da Atividade Orientadora de Ensino (motivos, objetivos, ações, operações, condições). Alguns professores manifestaram dificuldade em identificar os elementos estruturantes da AOE, como a SDA, confundindo-a com uma simples contextualização.

Outros professores apresentaram reflexões que estão ligadas com os princípios da AOE, onde o professor, para materializar uma proposta de trabalho junto aos estudantes, apresenta a SDA como ação central e mediadora entre a atividade de ensino e a atividade de aprendizagem, como é possível observar na fala de uma das professoras:

[...] alguns conhecimentos matemáticos que eu não conhecia eu tive que ir atrás, num estudo teórico pra eu poder ter um embasamento pra dar as minhas respostas, foi exatamente um dos objetivos que vocês queriam propiciar com essas atividades, eu não fiz um esquema porque eu tenho dificuldade em fazer no computador, mas eu fiz aqui no meu caderno e eu relacionei assim: Conteúdos científicos teóricos e de outro lado a atividade de ensino; na atividade de ensino, tendo o professor como vocês, como eu descrevi na minha resposta e nós o aluno na atividade de ensino, nós somos o que? O sujeito dessa situação, quais são as nossas necessidades? Do aluno que somos nós de aprender, e de vocês no caso, na função de professor de nos ensinar né, de transpassar esse conhecimento. E os motivos, de vocês uma organização desse ensino né, para estar viabilizando nosso conhecimento e nós a assimilação dos conhecimentos teóricos, pelo menos a gente ler, internaliza e faz outras pesquisas para assimilar esse conhecimento teórico, aí a gente vem 'pras' ações que vocês sentaram com certeza, se reuniram viram as definições e procedimentos de como trabalhar com esse conhecimento teórico conosco, como nos indagar, nos questionar, nos provocar em relação a um conhecimento e nós ficamos com as ações da resolução do problema de aprendizagem, nós queremos aprender, mas nós precisamos chegar em uma solução, precisamos estudar isso para chegar a uma conclusão (E2, PA, vídeo).

Assim, através deste episódio, foi possível identificar ações que foram desencadeadas pela situação proposta, tanto para suprir a necessidade de compreender o conteúdo estatístico no processo de resolução da situação quanto de reflexão sobre a teoria a partir da leitura realizada. Percebe-se, na fala da professora, a conscientização sobre o seu processo de aprendizagem e reconhecimento de suas ações. Dessa forma, pode-se concluir que a situação apresentada despertou necessidades que levaram alguns professores a estar em atividade, mesmo que isso não tenha ocorrido com os outros participantes.

\section{Episódio 3: Manifestações dos conceitos estatísticos}

Este episódio pretende revelar como os professores se relacionaram com os conceitos estatísticos a partir da situação desencadeadora proposta. Estas relações serão apresentadas através de duas cenas, a primeira sobre as manifestações dos conceitos no movimento de solução coletiva do problema desencadeador, e a segunda sobre as relações estabelecidas no ensino de estatística. 
O momento da resolução do problema desencadeador se divide em dois momentos: as soluções individuais e as discussões com mediação dos organizadores. Nas soluções individuais dos professores, foi possível perceber que nem todos recorreram a ferramentas matemáticas ou conceitos estatísticos, estabelecendo relações sociais e comparações com a covid-19 para afirmar a necessidade do isolamento.

Apenas um professor (PC) buscou utilizar a porcentagem como recurso, estabelecendo a taxa de letalidade da doença nas duas cidades. Outros docentes construíram gráficos de barras, contudo com diferentes intenções: alguns deles buscavam identificar as mortes ao longo do tempo e outros buscavam comparar o número de mortes nas duas cidades. Contudo, é necessário lembrar que gráficos de barras não têm a função de estabelecer mudanças ao longo do tempo. O estabelecimento de comparações não seria de todo errado, entretanto, pela falta da informação sobre a população, não era possível interpretar o que significava o gráfico. Assim, o gráfico de barras, quando utilizado, possuía apenas a função de representar a mesma informação do texto, sem contribuições para a interpretação e comparação de dados.

Uma das professoras (PG) que também sentiu a necessidade de representar os dados ao longo do tempo utilizou algo próximo ao gráfico de linhas (Figura 4), entretanto, não foi possível reconhecer o motivo que a levou a definir diferentes concavidades para ligar os números de mortos das duas cidades. Como hipótese, pode-se pensar que a participante estivesse influenciada pelo formato do crescimento exponencial ou logarítmico ou ainda estivesse preocupada com a diferença de dias entre os dados, mas não há informação suficiente para esta análise.

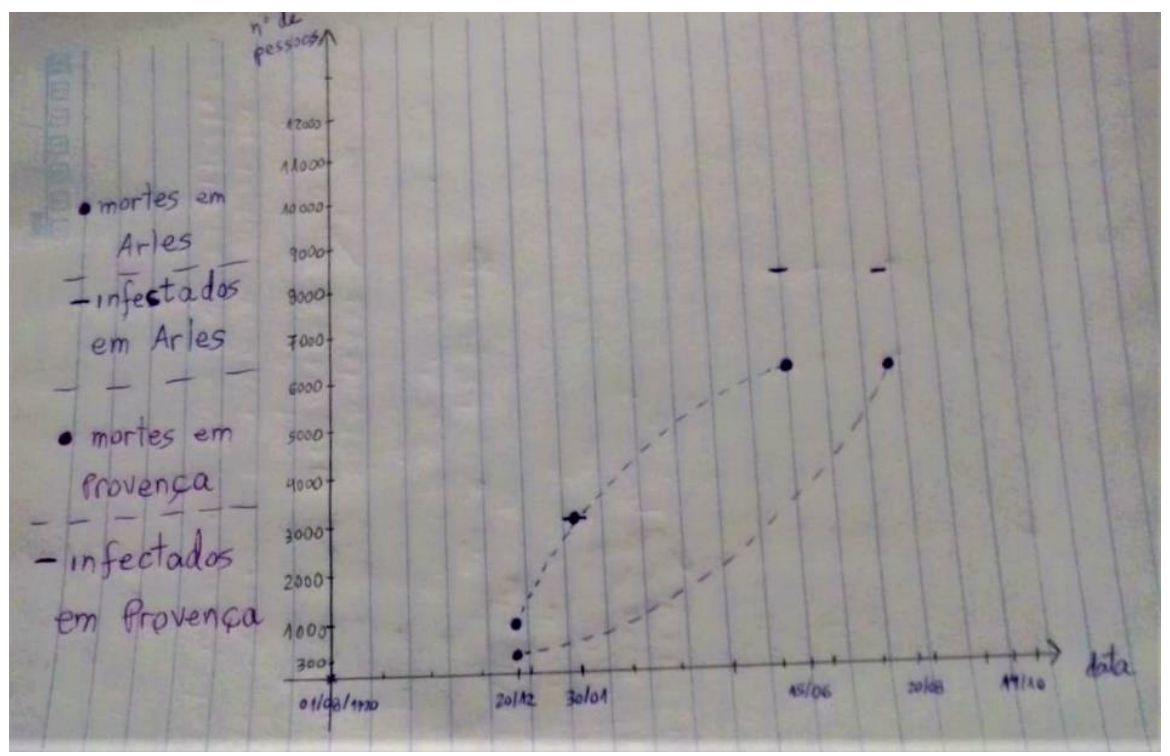

Figura 4 - Solução individual de uma professora Fonte: Autores

Ainda buscando entender como os professores compreendiam o movimento dos dados em função do tempo, percebeu-se que um dos docentes $(\mathrm{PH})$ considerou o número de mortos estável entre uma e outra notícia, isto é, considerou o movimento do recolhimento de dados 
feito por Augusta e não o movimento (mais gradativo) da doença.

Apenas duas professoras relataram, na solução individual, que sentiram falta de dados, mas não especificaram quais. No momento da mediação, isto é, da discussão coletiva, quando perguntados de qual informação seria necessária para relativizar os dados entre as cidades, finalmente surge a necessidade de se saber a população.

Como que eu vou saber que 6 mil mortes em Provença é uma porcentagem se eu não sei a quantidade de habitantes em Provença naquele momento? (E1, PA, vídeo).

A partir disso, a mediação dos organizadores voltou-se para o que fazer com essa informação:

[...] eu não tenho [o número de] recuperados, mas eu vou calcular naquela época a quantidade de mortos que foram, para eu saber a porcentagem da população que foi efetivamente morta naquele momento, mas eu também poderia estar utilizando para comparar as duas cidades (E1, PA, vídeo).

Quando questionados sobre como organizar e interpretar dados de uma região toda, surgiram duas possibilidades estatisticamente válidas: somar os dados e estabelecer as taxas a partir do todo ou estabelecer uma média dos dados e, consequentemente, a taxa média - fato este que demonstra que no decorrer das discussões os professores passaram a recorrer aos conceitos estatísticos para responder aos questionamentos colocados.

Não houve muita discussão sobre as formas de representação. Apesar disso, é válido destacar a fala de um professor (PC) sobre como os gráficos podem mudar a visão que se tem sobre os dados:

[...] se o jornal colocasse essa informação em gráfico, iria assustar muito mais, porque um gráfico melhora significativamente a compreensão da situação, acho que também colocando em torno de números seja uma estratégia para não assustar a população (E1, PC, vídeo).

Ao fim dessa cena, é possível concluir que a situação desencadeadora por si só não suscitou a necessidade de conceitos estatísticos em todos os professores e que, quando isso ocorreu, não necessariamente estes docentes fizeram uma reflexão sobre como os instrumentos escolhidos realmente auxiliavam na interpretação dos dados. A mediação, assim como esperado teoricamente, foi um elemento essencial para despertar as necessidades e discussões sobre os conceitos, sendo possível perceber que os professores começaram a olhar criticamente o conjunto de dados ofertado na situação.

Ainda que houvesse a expectativa de estabelecer os nexos conceituais do conhecimento estatístico e o movimento de pensamento teórico dos participantes da OPM, há que se considerar que apenas uma situação de ensino não tem condições de evidenciar o que se espera ser atingido ao longo de um processo de estudo e formação.

A segunda cena, sobre o papel dos conceitos estatísticos no processo de ensino, é mais curta. Isso se deve ao fato de que poucos professores leram o texto indicado e que este não era o foco da situação. Mesmo assim, após a leitura do texto, uma das professoras (PB) fez uma relação entre os conceitos estatísticos e as atividades de ensino e de aprendizagem: 
DOI: $10.20396 /$ zet.v29i00.8661815

[...] o que cabe ao professor [é] desenvolver a capacidade de ensino, no caso a atividade de ensino é análise de dados estatísticos, já o aluno, o que ele tinha que fazer, atividade de aprendizagem, [...] [é] compreender como a leitura de dados estatísticos auxilia na leitura, compreensão e interpretação de fenômenos. (E2, PB, vídeo).

Dessa forma, é possível perceber que ela está compreendendo que a análise estatística é papel do professor, e aos estudantes cabe a leitura dessas análises para compreensão de fenômenos. Contudo, é necessário ressaltar que esta visão do ensino não reflete as relações da AOE e não desenvolve a autonomia dos estudantes, que sempre dependeriam de uma ação prévia do professor para interpretação de dados. Portanto, essa fala permite perceber que as situações desencadeadoras de aprendizagem (e consequentemente o modo de ação da OPM) não são familiares aos professores.

\section{Considerações finais}

Neste trabalho, o fenômeno "conhecimento estatístico manifestado pelos professores dos anos iniciais no movimento da OPM" foi analisado pelo isolado do movimento de resolução do problema apresentado pela situação "O Diário da Peste Bubônica". A situação foi intencionalmente criada considerando relações essenciais do conhecimento estatístico e episódios do seu movimento histórico e lógico. Um recorte desse movimento foi a seleção do registro histórico do tensionamento vivido pela sociedade inglesa no período da peste bubônica, quando os registros de Johan Graunt mostraram um modo de organização e análise de dados para reconhecer as causas das mortes, auxiliando nas tomadas de decisão diante daquele problema. Este episódio e os nexos conceituais estabelecidos por Moura et al. (2019) foram considerados na elaboração da situação desencadeadora de aprendizagem, visando ao desenvolvimento do pensamento em sua forma teórica (Silva et al., 2020).

Destaca-se que os dados disponibilizados no diário da personagem Augusta, que compõe a situação desencadeadora de aprendizagem, são complexos, além de intencionalmente não estarem completos e nem apresentarem regularidade temporal. Pretendia-se que, a partir desta situação, fosse gerada a necessidade de reconhecer outros dados mais regulares, identificando-os como variáveis a serem relacionadas. A partir das discussões dos professores sobre a busca pela solução do problema proposto no Diário, foi feita a análise em busca das manifestações dos docentes sobre o conhecimento estatístico. Assim, para estabelecer a análise, compreendeu-se a (re)constituição do isolado por três episódios: necessidades despertadas pela situação, ações despertadas pela situação, e manifestações dos conceitos científicos.

Assim, foi possível reconhecer que a situação desencadeou necessidades de dados socioeconômicos da época e dados quantitativos da doença, além da necessidade colocada pelo problema de tomar uma decisão com tais informações disponibilizadas. Para supri-las, os professores demonstraram ações de pesquisa e de representação dos dados. Outra ação evidenciada foi a relação entre a situação colocada e os elementos da Atividade Orientadora de Ensino. 
DOI: $10.20396 /$ zet.v29i00.8661815

Também foi possível analisar como os professores se relacionaram com os conceitos estatísticos a partir da situação desencadeadora proposta. Estas relações foram observadas no movimento de solução coletiva e nas reflexões sobre o ensino de Estatística. No que se refere às soluções individuais dos professores, foi possível perceber que nem todos utilizaram ferramentas matemáticas ou conceitos estatísticos, estabelecendo relações sociais e comparativas com a covid-19 para chegar a uma conclusão sobre isolar-se ou não. Duas professoras relataram que sentiram falta de dados, mas não mencionaram quais. Durante o movimento de discussão e análise coletiva da situação, os professores passaram a recorrer aos conceitos estatísticos para formular um posicionamento. Foi possível perceber que a situação desencadeadora sozinha não despertou a necessidade dos conceitos estatísticos em todos os professores, mas que durante a mediação, os professores refletiram criticamente sobre o conjunto de dados apresentado na situação, estabelecendo mais relações.

O reconhecimento, a análise e a representação dos dados são movimentos próprios da estatística, contudo não refletem os nexos conceituais desta área. Para compreender como os professores confrontam os nexos conceituais, buscou-se qual a relação entre eles e o movimento de solução do problema posto pela situação desencadeadora:

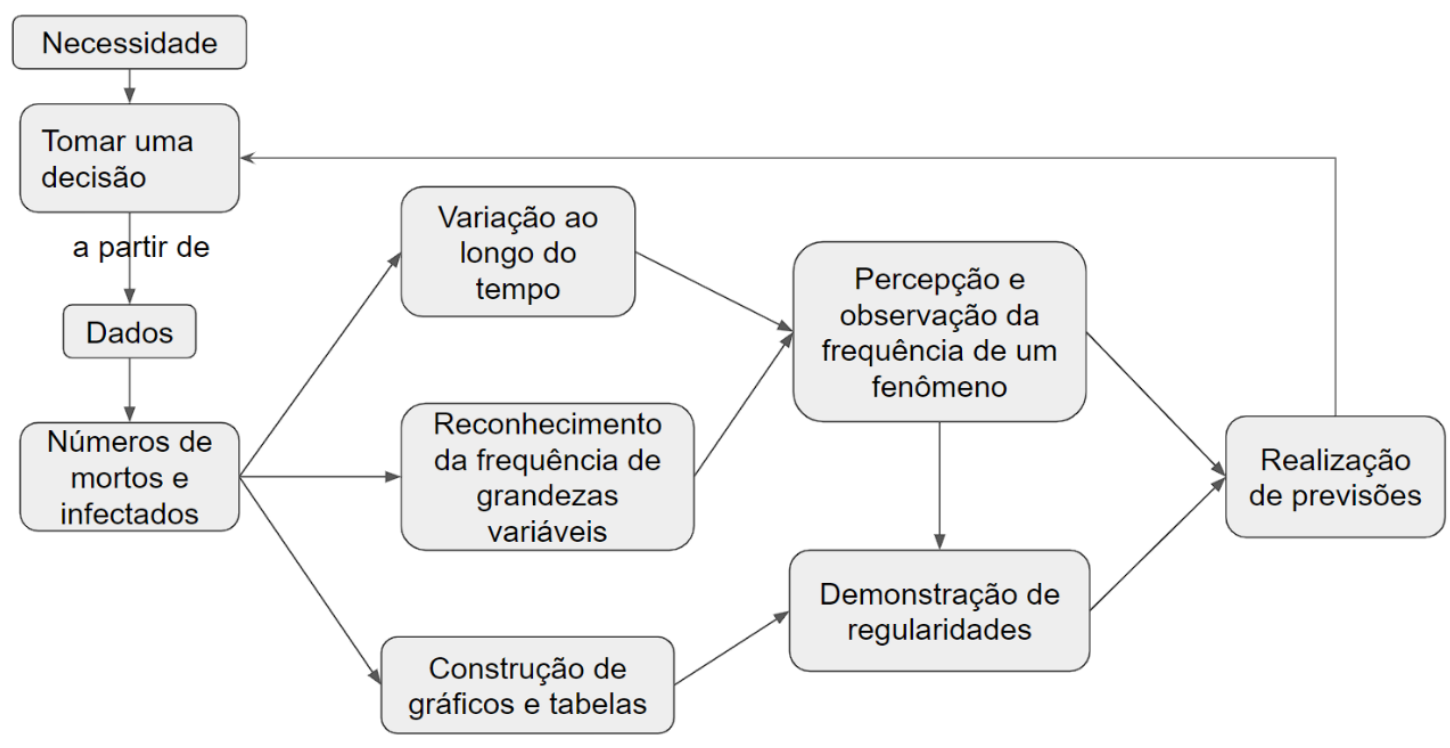

Figura 5 - Relações entre a situação proposta e os nexos conceituais da Estatística Fonte: Oliveira et al., 2020, p. 164.

Dessa forma, mesmo que a situação tenha sido resolvida com um conjunto restrito de conceitos, principalmente taxas, variáveis e gráficos que não possibilitaram aos professores reconhecer padrões e regularidades, pode-se entender que ela permitiu análises e discussões que alcançaram alguns dos nexos conceituais da estatística propostos por Moura et al. (2019). Como este movimento não foi espontâneo dos docentes, destaca-se a importância da continuidade de ações como as da Oficina Pedagógica de Matemática na apresentação para os professores sobre o movimento histórico-lógico das diversas áreas do conhecimento, em especial, da Estatística. 
DOI: $10.20396 /$ zet.v29i00.8661815

Além disso, destaca-se o papel da situação desencadeadora proposta para despertar necessidades e suscitar o movimento dos conhecimentos estatísticos dentro do projeto. Entende-se que este instrumento possibilitou tais discussões devido às suas características, em especial o fato de conter um problema desencadeador que foi planejado para trabalhar compreensões do movimento histórico-lógico (Silva et al., 2020). Ainda que o planejamento de uma situação não necessariamente reflita as particularidades da prática, entende-se que a intencionalidade posta na situação e na mediação é ponto fundamental para os resultados encontrados.

Portanto, este artigo apresenta a análise de uma das ações da Oficina Pedagógica de Matemática em 2020. Tomando esta ação como isolado, foi possível perceber como os professores participantes se relacionam com o conhecimento estatístico e como movimentos de formação, como os da OPM, são importantes para modificar qualitativamente estas relações. É válido ressaltar que esta análise, pela característica de isolado, não se propõe a compreender todas as relações existentes entre estes docentes e a Estatística, mas busca observar as manifestações delas em registros de dois encontros do projeto realizados de forma virtual e de suas respectivas tarefas. Tal análise, se efetuada com outros professores, outra situação ou em outras condições, poderia obter resultados diferentes, ficando a possibilidade de novas investigações sobre a apropriação de conhecimentos estatísticos por professores em formação continuada. Ao fim deste estudo, nas condições em que foi realizado, é possível perceber que, apesar de o movimento formativo da Oficina Pedagógica de Matemática não ser habitual para os professores participantes, a situação proposta despertou motivos e ações que possibilitaram a reflexão sobre relações essenciais do conhecimento estatístico.

\section{Referências}

Bernstein, P. L. (2018). Desafio aos Deuses: A fascinante História do Risco. Rio de Janeiro: Alta Books.

Campos, C. R., Wodewotzki, M. L. L., \& Jacobini, O. R. (2013). Educação Estatística: teoria e prática em ambientes de modelagem matemática. Belo Horizonte: Autêntica.

Caraça, B. J. (1978). Conceitos Fundamentais da Matemática. Lisboa: Gradiva.

Cedro, W. L. (2008). O motivo e a atividade de aprendizagem do professor de Matemática: uma perspectiva histórico-cultural. Tese de Doutorado em Educação. São Paulo: Universidade de São Paulo. Retirado em 29 de outubro, 2020, de: https://www.teses.usp.br/teses/disponiveis/48/48134/tde-17122009080649/publico/Tese_Wellington_Cedro.pd

Conti, K. C., Carvalho, D. L. De, \& Carvalho, C. F. De. (2016). Desenvolvimento profissional de professores potencializado pelo contexto colaborativo para ensinar e aprender estatística. Revista Eletrônica de Educação, 10(2), 155-171. https://doi.org/10.14244/198271991439

Davydov, V. V. (1988). Tipos de generalización en la enseñanza. Havana: Pueblo y Educación. 
DOI: $10.20396 /$ zet.v29i00.8661815

Gal, I. (2004) Statistical literacy: Meanings, components, responsabilities. In D. Ben-Zvi, \& J. Garfield (Edts.), The challenge of developing statistical literacy, reasoning and thinking (pp. 47-78). Dordrecht: Kluwer.

Kopnin, P. V. (1978). A dialética como lógica e teoria do conhecimento. Rio de Janeiro: Civilização Brasileira.

Leontiev, A. N. (1978). O desenvolvimento do psiquismo. Lisboa: Livros Horizonte.

Lopes, C. E., \& Meirelles, E. (2005). Estocástica na Séries Iniciais. XVIII Encontro Regional de Professores de Matemática (pp. 1-8). Campinas: Anais. Retirado em 10 de setembro, 2020, de https://www.ime.unicamp.br/erpm2005/anais/m_cur/mc02_b.pdf

Memória, J. M. P. (2004). Breve História da Estatística. Brasília: Embrapa informação tecnológica.

Moura, M. O. (1994). Pesquisa colaborativa: um foco na ação formadora. In: Barbosa, R. L. L. (org). Trajetórias e perspectivas na formação de educadores. São Paulo: Editora UNESP.

Moura, M. O. (1998). Oficina Pedagógica de Matemática. In Encontro Nacional de Educação Matemática, Maringá, Paraná, Brasil, 2.

Moura, M. O., Araujo, E. S., \& Serrão, M. I. B. (2019). Atividade Orientadora de Ensino: fundamentos. Linhas Críticas, 24. https://doi.org/10.26512/lc.v24i0.19817

Moura, M. O., Araújo, E. S., Moretti, V. D., Panossian, M. L., \& Ribeiro, F. D. (2010). Atividade Orientadora de Ensino: unidade entre ensino e aprendizagem. Revista Diálogo Educacional, $10 \quad$ (29), 205-229. Disponível em: https://periodicos.pucpr.br/index.php/dialogoeducacional/article/download/3094/3022.

Moura, M. O. (1996). A Atividade de Ensino como Unidade Formadora. Bolema: Boletim de Educação Matemática, 11 (12), 1-14. Disponível em: https://edisciplinas.usp.br/mod/resource/view.php?id=2316462.

Moura, M. O. (Org.). (2016). A Atividade Pedagógica na Teoria Histórico-Cultural. Campinas: Autores Associados. 2. ed.

Moura, M. O., Lopes, A. R. L. V., Araújo, E. S., \& Cedro, W. L. (org). (2019). Estatística (Vol. 1, Coleção atividades para o ensino de matemática nos anos iniciais da Educação Básica).

Moraes, S. P. G., Arrais, L. F. L., Gomes, T. S., Graciliano, E. C., \& Vignoto, J. (2012). Pressupostos teórico-metodológicos para formação docente na perspectiva da teoria histórico-cultural. Revista Eletrônica de Educação, 6 (2), 138-155.

Moraes, S. P. G. de, Lazaretti, L. M., \& Lacanallo Arrais, L. F. (2019). Formar formando: o movimento de aprendizagem docente na Oficina Pedagógica de Matemática. Obutchénie: Revista De Didática E Psicologia Pedagógica, 2(3), 643-668. https://doi.org/10.14393/OBv2n3.a2018-47439.

Oliveira, N. M., Vilas Boas, F. P., Fabri, G. J. C., Mancini, P. H. M., \& Silva, R. A. (2020) O Isolamento de Augusta. In M. L. Panossian \& Tocha, N. N. (Orgs.), Estabelecendo Parâmetros de Análise de Situações de Ensino de Conteúdo Matemático: aproximações a partir da Atividade Orientadora de Ensino (pp.159-166). Curitiba: OPM. 
Oliveira Júnior, A. P., \& Vieira, M. L. (2018). Validação e Avaliação das Atitudes de Professores dos Anos Iniciais do Ensino Fundamental em Relação ao Ensino de Estatística. Alexandria: Revista de Educação em Ciência e Tecnologia, 11(1), 149-171. http://dx.doi.org/10.5007/1982-5153.2018v11n1p149.

Panossian, M. L., Silva, A. L., Pallu, F., \& Oliveira, L. S. (2018). A oficina pedagógica de matemática como atividade. Obutchénie: Revista de Didática e Psicologia Pedagógica, 1(4), 14-39. https://doi.org/10.14393/OBv2n1a2018-2.

Poubel, M. W., \& Sad, L. A. (2014). De contagens empíricas e jogos ao poder da Ciência Estatística. Revista de História da Matemática para Professores, 1(1), 21-27.

Shulman, L. S. (1987). Knowledge and teaching: foundations of the new reform. Harvard Educ.Rev., 57(1), 1-22.

Silva, A. da F. G., Alves, T. A. S., Pietropaolo, R. C., \& Amorim, M. É. (2020). Propriedades da Média: um estudo sobre respostas dadas por professores para casos de ensino. Educação Matemática em Revista, 25(66), 184-200.

Silva, R. A., Oliveira, N. M., Mancini, P. H. M., \& Panossian, M. L. (2020). O Movimento de Formação Docente nas Reformulações de uma Situação Desencadeadora de Aprendizagem. In I Encontro Nacional Online de Professores Que Ensinam Matemática, 2020. Disponível em:

http://matematicanaescola.com/eventos/index.php/ienopem/ienopem/paper/view/30.

Tabak (2004). Probability and Statistics: the science of uncertainty. New York: Facts on File.

Wild C.J., Utts J.M., Horton N.J. (2018) What Is Statistics?. In D. Ben-Zvi, K. Makar, J. Garfield (Eds), International Handbook of Research in Statistics Education. Springer International Handbooks of Education. Springer, Cham. https://doi.org/10.1007/978-3319-66195-7.

Vygotsky, L. S. (1998). A formação social da mente. São Paulo: Martins Fontes. 